\title{
PENGARUH KUALITAS PELAYANAN, SUASANA TOKO, DAN LOKASI TERHADAP KEPUTUSAN PEMBELIAN DI INDOMARET JALAN SULTAN ISKANDAR MUDA KEBAYORAN LAMA
}

\author{
Husnul Hotimah,Lucy Nancy* \\ *)Dosen Tetap Program S1 Jurusan Manajemen Fakultas Ekonomi Universitas Satya Negara Indonesia \\ Email: husnulh6@gmail.com; mamaolgalucy@co.id
}

\begin{abstract}
This study aims to determine the effect of Service Quality, AtmosphereStore, and Location on Purchasing Decisions at Indomaret Jalan Sultan Iskandar Muda Kebayoran Lama. The population in this study all consumers who made purchases at Indomaret Jalan Sultan Iskandar Muda Kebayoran Lama and the sample in this study amounted to 71 consumer. The design of this study uses a causal method. The sampling technique uses accidental sampling. The method of collecting data uses primary data and secondary data.The data analysis method used in this study is multiple linear regression analysis with the help of SPSS 22 Software.The results showed that partially (t test) Service Quality $\left(X_{1}\right)$ and AtmosphereStore $\left(X_{2}\right)$ had a significant effect on Purchasing Decisions, while Location $\left(X_{3}\right)$ had no significant effect on Purchasing Decisions.Simultaneously ( $F$ test) shows that there is a significant influence between Service Quality variables (X1), AtmosphereStore (X2) Location (X3) on Purchase Decisions (Y).And the contribution of all adjusted $R^{2}$ independent variables is 49,6\% towards Purchasing Decisions (Y), while the remaining 50,4\% is explained by other factors or variables unknown and not included in this study.
\end{abstract}

\section{Keywords: Service Quality, AtmosphereStore, and Purchasing Decision}

\section{PENDAHULUAN}

Seiring dengan perkembangan zaman, keberadaan bisnis ritel modern menjadi semakin penting karena adanya pergeseran pola belanja masyarakat yang lebih suka berbelanja di pasar ritel modern seperti minimarket, supermarket, ataupun hypermart. Masyarakat lebih gemar berbelanja di pasar ritel modern karena masyarakat bisa mendapatkan kepraktisan dan kecepatan dalam berbelanja. Tuntutan kebutuhan akan tempat belanja yang aman, lokasi yang mudah dicapai, ragam barang yang tinggi, nyaman sekaligus dapat dijadikan sebagai tempat rekreasi, sehingga tidak hanya sebagai tempat menjual barang dagangan saja. Selain itu, perubahan gaya hidup masyarakat yang lebih membutuhkan kemudahan untuk berbelanja menjadi penyebab menjamurnya bisnis ritel atau eceran.

Berdasarkan observasi data sekunder yang dilakukan peneliti menemukan terjadinya fluktuasi pada penjualan di Indomaret Jalan Sultan Iskandar Muda Kebayoran Lama.

Tabel 1

Data Penjualan Indomaret Jalan Sultan Iskandar Muda Januari - Juli 2019

\begin{tabular}{|l|l|l|l|}
\hline Bulan & Target & Pencapaian & Presentase \\
\hline Januari & 480.000 .000 & Rp. 511.356.780 & $106,5 \%$ \\
\hline Februari & 450.000 .000 & Rp. 453.335 .354 & $100,7 \%$ \\
\hline Maret & 450.000 .000 & Rp. 335.225.354 & $74,4 \%$ \\
\hline April & 480.000 .000 & Rp. 522.845.967 & $108.9 \%$ \\
\hline Mei & 480.000 .000 & Rp. 537.337.876 & $111,9 \%$ \\
\hline
\end{tabular}




\begin{tabular}{|l|l|l|l|}
\hline Juni & 480.000 .000 & Rp. 612.656.763 & $127,6 \%$ \\
\hline Juli & 450.000 .000 & Rp. 325.548.760 & $72,3 \%$ \\
\hline
\end{tabular}

Sumber: Data Penjualan Indomaret

Berdasarkan dari data penjualan Indomaret Jalan Sultan Iskandar Muda Kebayoran Lama diatas terlihat terjadi fluktuasi penjualan. Terjadi penurunan dan kenaikan yang tidak stabil pada total penjualan dari tiap bulannya. Total penjualan terendah terjadi pada bulan Juli sebesar Rp. 325.548.760 dengan presentase $72,3 \%$. Dan total penjualan tertinggi terjadi pada bulan Juni sebesar Rp. 612.656 .763 dengan presentase 127,6\%. Total penjualan yang rendah menunjukkan bahwa hanya sebagian kecil konsumen yang melakukan pembelian.

Berdasarkan latar belakang diatas, peneliti tertarik untuk memilih Judul " PENGARUH KUALITAS PELAYANAN, SUASANA TOKO, DAN LOKASI TERHADAP KEPUTUSAN PEMBELIAN DI INDOMARET JALAN SULTAN ISKANDAR MUDA KEBAYORAN LAMA".

\section{TINJAUAN PUSTAKA}

\section{Keputusan Pembelian}

Menurut Kotler dan Armstrong (2012:177) Keputusan Pembelian merupakan bagian dari perilaku konsumen yaitu studi tentang bagaimana individu, kelompok, dan organisasi memilih, membeli, menggunakan, dan bagaimana barang barang jasa, ide atau pengalaman untuk memuaskan kebutuhan keinginan mereka.

Perilaku konsumen akan menentukan proses pengambilan keputusan dalam pembelian mereka, proses tersebut merupakan sebuah pendekatan penyesuaian masalah yang terdiri dari lima tahap yang dilakukan konsumen, kelima tahap tersebut adalah pengenalan masalah, pencarian informasi, evaluasi alternatif, membuat keputusan pembelian, dan perilaku pasca pembelian.

\section{Kualitas Pelayanan}

Menurut Tjiptono dan Chandra (2016:115) kualitas pelayanan sebagai kondisi dinamis yang berhubungan dengan produk, jasa, sumber daya manusia, proses, dan lingkungan yang memenuhi atau melebihi harapan.

Perkembangan perusahaan menciptakan persaingan yang ketat. Berbagai cara dilakukan agar dapat memperoleh pelanggan dan mempertahankannya. Salah satu strategi yang dipakai perusahaan untuk bisa memenangkan persaingan adalah dengan kualitas layanan yang baik.Pelanggan tertarik membeli sebuah produk atau jasa karena kualitas layanan yang baik.

\section{Suasana Toko}

Menurut Christina Whidya Utami (2010:25) Suasana Toko merupakan kombinasi dari karakteristik fisik toko seperti arsitektur, tata letak, pencahayaan, pemajangan, warna, temperatur, musik, aroma yang secara menyeluruh akan menciptakan citra dalam benak konsumen.

Suasana toko merupakan salah satu faktor yang mampu untuk menarik perhatian konsumen.Dengan adanya suasana toko yang baik, perusahaan dapat menarik konsumen untuk berkunjung dan melakukan pembelian.Suasana toko mempengaruhi keadaan emosi konsumen yang dapat menyebabkan atau mempengaruhi konsumen tersebut untuk melakukan pembelian.

\section{Lokasi}


Menurut Ratih Hurriyati (2015:56) dikatakan bahwa Tempat (Place) diartikan sebagai tempat pelayanan jasa, berhubungan dengan di mana perusahaan harus bermarkas dan melakukan operasi atau kegiatannya.

Strategi lokasi adalah salah satu determinasi yang paling penting dalam perilaku konsumen, perusahaan harus memilih lokasi yang strategis dalam menempatkan tokonya disuatu daerah yang dekat dengan keramaian dan aktifitas masyarakat. Karena apabila terjadi kesalahan dalam memilih lokasi akan berpengaruh besar bagi kelangsungan hidup pemilihan usaha bisnis. Lokasi juga akan mempengaruhi jumlah konsumen yang akan datang, lokasi yang strategis, lokasi yang mudah di jangkau menggunakan transportasi, serta memiliki kapasitas yang cukup untuk konsumen yang berkunjung.

\section{Penelitian Terdahulu}

Mohammad Yusuf Affandi (2017) penelitian yang berjudul "Pengaruh Kualitas Pelayanan, Atmosfer Toko, Dan Harga terhadap Keputusan Pembelian Di Ria Mart". Menyatakan bahwa hasil penelitian variabel Kualitas Pelayanan berpengaruh signifikan terhadap Keputusan Pembelian.

Rinna Rahmawati, Musriha, Indah Noviandari (2017) penelitian yang berjudul "Pengaruh Store Atmosphere, Kualitas Pelayanan, dan Merek Pribadi terhadap Keputusan Pembelian pada Kue Liarah Surabaya Periode 2013-2015". Menyatakan bahwa variabel Store Atmosphereberpengaruh signifikan terhadap Keputusan Pembelian.

Febriano Clinton Polla, Lisbteh Mananeke dan Rita N Taroreh (2018) penelitian yang berjudul "Pengaruh Harga, Promosi, Lokasi, dan Kualitas Pelayanan terhadap Keputusan Pembelian pada PT. Indomaret Manado Unit Jalan Sea" Menyatakan bahwa variabel Lokasiberpengaruh signifikan terhadap Keputusan Pembelian.

\section{Kerangka Pemikiran}

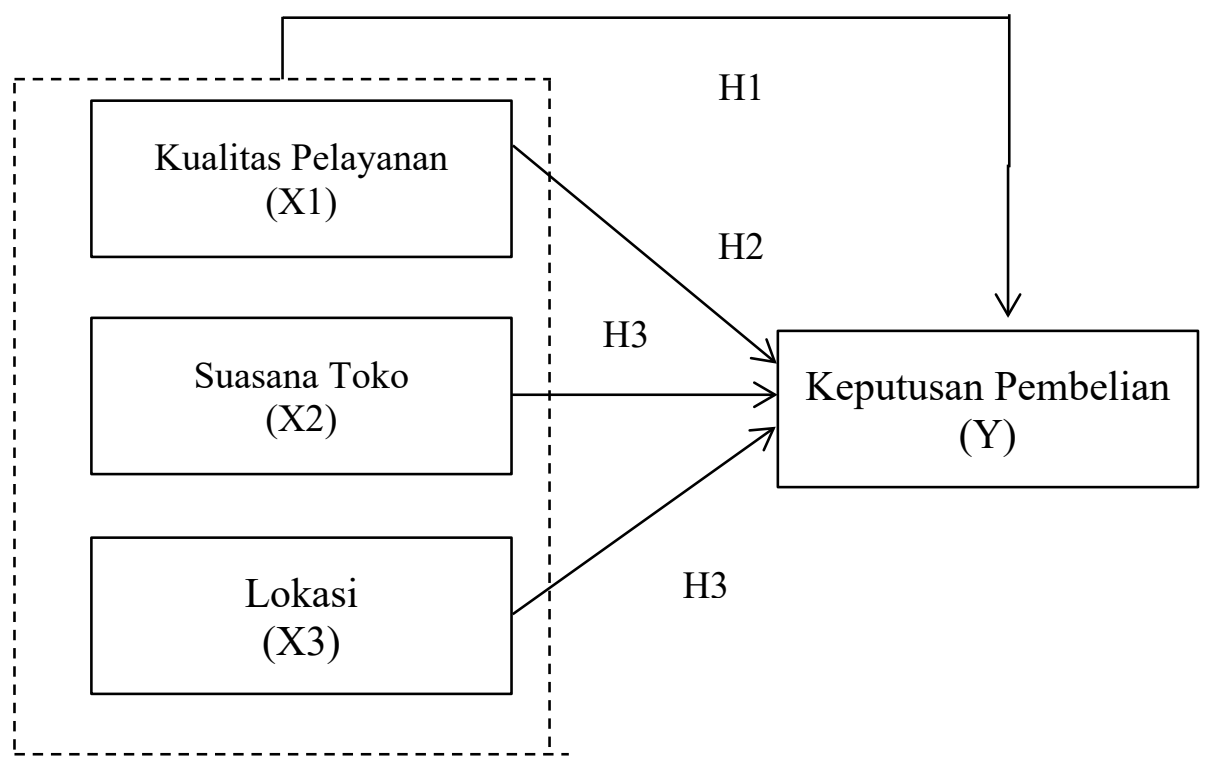

\section{Hipotesis}


H1 : Kualitas Pelayanan, Suasana Toko, dan Lokasi memiliki berpengaruh terhadap Keputusan Pembelian di Indomaret.

H2 : Kualitas Pelayanan berpengaruh terhadap Keputusan Pembelian di Indomaret

H3 : Suasana Toko berpengaruh terhadap Keputusan Pembelian di Indomaret

H4 : Lokasi berpengaruh terhadap Keputusan Pembelian di Indomaret

\section{METODOLOGI PENELITIAN}

\section{Waktu dan Tempat Penelitian}

Waktu yang dilakukan untuk melaksanakan penelitian ini pada bulan April 2019 sampai dengan Juni 2019. Tempat penelitian dilakukan di Indomaret yang beralamat di Jalan Sultan Iskandar Muda No.9 RT.08/RW.04 Kebayoran Lama, Jakarta Selatan, Daerah Khusus Ibukota Jakarta 12240.

\section{Desain Penelitian}

Desain penelitian yang digunakan adalah penelitian Kausal (Causal Research) yang merupakan penelitian untuk mengetahui hubungan satu variabel atau lebih variabel bebas (Independent Variable) terhadap variabel terikat (Dependent Variable).

\section{Metode Pengumpulan Data}

Untuk memperoleh data dan informasi yang dibutuhkan penulis, maka metode pengumpulan data yang digunakan dalam penelitian ini adalah sebagai berikut:

a. Studi Kepustakaan

dengan membaca dan mempelajari buku-buku dan literatur-literatur yang berhubungan dengan masalah yang akan diteliti, guna memperoleh data teoritis yang relevan dengan pokok persoalan yang dibahas

b. Penelitian Lapangan

Penelitian lapangan dilakukan dengan mengadakan penelitian langsung pada objek atau perusahaan yang akan diteliti untuk mengumpulkan data yang diperlukan tersebut melalui: wawancara dan kuesioner

\section{Populasi dan Sampel}

Populasi dalam penelitian ini adalah seluruh konsumen Indomaret Jalan Sultan Iskandar Muda No.9 Wilayah Kebayoran Lama.Dalam penelitian ini, teknik sampling yang digunakan oleh peneliti adalah teknik Non Probability Sampling. Metode pengambilan sampel dalam penelitian adalah dengan menggunakan Accidental Sampling.

Penetapan sampel menggunakan rumus Roscoe dalam Sugiyono (2016:91), yaitu :

$$
\mathrm{n}=(10) \mathrm{x} \mathrm{k}
$$

$\mathrm{n}=(10) \times 4=40$

Keterangan:

$\mathrm{n}$ : Jumlah Sampel

$\mathrm{k}$ : Variabel penelitian yang digunakan

10 : Jumlah observer menurut pendapat Roscoe 
Mengingat berbagai pertimbangan seperti waktu, tenaga, fasilitas, dan kondisi maka sampel yang digunakan sebanyak 120 responden. Setelah melalui uji Normalitas data,data yang dapat diolah hanya sebanyak 71 responden terdapat beberapa data yang ektrem yang harus di keluarkan.

\section{ANALISIS HASIL DAN PEMBAHASAN}

\section{Uji Deskriptif}

Analisis deskriptif digunakan untuk menggambarkan tentang statistik data seperti min, max, mean, sum, standard deviasi, variance, range, dan lain-lain, untuk mengukur distribusi data.

\section{Tabel. 2}

Hasil Uji Deskriptif

Descriptive Statistics

\begin{tabular}{|l|l|l|l|l|l|}
\hline & N & Minimum & Maximum & Sum & Mean \\
\hline Kualitas Pelayanan & 71 & 32 & 74 & 3907 & 55.03 \\
Suasana Toko & 71 & 27 & 59 & 3225 & 45.42 \\
Lokasi & 71 & 22 & 40 & 2316 & 32.62 \\
Keputusan Pembelian & 71 & 33 & 58 & 3192 & 44.96 \\
Valid N (listwise) & 71 & & & & \\
\hline
\end{tabular}

Sumber: Output SPSS Ver.22, 2019

\section{Uji Validitas}

Menurut Duwi Priyatno (2017:63) uji validitas item merupakan uji instrumen data untuk mengetahui seberapa cermat suatu item dalam mengukur apa yang ingin diukur pada kuesioner.Hasil yang didapat penulis merupakn seluruh pernyataan valid, sesuai dengan hasil SPSS, dimana $r$ hitung $>r$ tabel.

\section{Uji Reliabilitas}

Menurut Duwi Priyatno (2017:79), uji realibilitas digunakan untuk mengetahui konsistensi alat ukur yang biasanya menggunakan kuesioner, maksudnya adalah alat ukur tersebut akan mendapatkan pengukuran yang tepat konsistensi jika pengukuran diulang kembali. Hasil yang didapat penulis merupakn seluruh pernyataan reliable, sesuai dengan hasil SPSS dengan nilai Cornbach Alpa $(\alpha)<0,60$ yang berarti reliable.

\section{Uji Asumsi Klasik}

Menurut Duwi Priyatno (2017:107), uji asumsi klasik digunakan untuk megatahui ada tidaknya normalitas residual, multikolinearitas, autokorelasi, dan heteroskedastisitas pada model regresi.

\section{Uji Normalitas}

Menurut Duwi Priyatno (2017:109) uji normalitas residual digunakan untuk menguji apakah nilai residual yang dihasilkan dari regresi terdistribusi normal atau tidak.Uji normalitas dalam penelitian ini menggunakan metode Kolmogrov Smirnov

\section{Tabel 3}




Hasil Uji Normalitas
Tests of Normality
\begin{tabular}{|l|l|l|l|}
\hline \multicolumn{1}{|l|}{} & \multicolumn{3}{l|}{ Kolmogorov-Smirnov } \\
\cline { 2 - 4 } & Statistic & Df & Sig. \\
\hline Kualitas Pelayanan & .090 & 71 & $.200^{*}$ \\
Suasana Toko & .068 & 71 & $.200^{*}$ \\
Lokasi & .098 & 71 & .086 \\
Keputusan Pembelian & .094 & 71 & $.200^{*}$ \\
\hline
\end{tabular}

Sumber: Output SPSS Ver.22, 2019

Dapat disimpulkan bahwa variabel Kualitas Pelayanan (X1), Suasana Toko(X2), Lokasi (X3), dan Keputusan Pembelian (Y) mempunyai nilai Kolmogorov-Smirnov > 0,05 maka, menunjukan bahwa data berdistribusi normal.

\section{Uji Multikolinieriras}

Menurut Duwi Priyatno (2017:120) multikolinieritas artinya antara variabel independen yang terdapat dalam model regresi memiliki hubungan linier yang sempurna atau mendekati sempurna (koefisien korelasinya tinggi atau bahkan 1).

\section{Tabel 4}

Hasil Uji Multikolinieritas

Coefficients $^{\mathbf{a}}$

\begin{tabular}{|c|c|c|c|c|c|c|c|c|}
\hline \multirow{2}{*}{\multicolumn{2}{|c|}{ Model }} & \multicolumn{2}{|c|}{$\begin{array}{c}\text { Unstandardized } \\
\text { Coefficients }\end{array}$} & \multirow{2}{*}{\begin{tabular}{|l|}
$\begin{array}{c}\text { Standardized } \\
\text { Coefficients }\end{array}$ \\
Beta \\
\end{tabular}} & \multirow[b]{2}{*}{$\mathrm{T}$} & \multirow[b]{2}{*}{ Sig. } & \multicolumn{2}{|c|}{$\begin{array}{c}\text { Collinearity } \\
\text { Statistics }\end{array}$} \\
\hline & & B & Std. Error & & & & $\begin{array}{l}\text { Toleranc } \\
\text { e }\end{array}$ & VIF \\
\hline \multirow[t]{4}{*}{1} & (Constant) & 5.148 & 6.256 & & .823 & .413 & & \\
\hline & $\begin{array}{l}\text { Kualitas } \\
\text { Pelayanan }\end{array}$ & .435 & .063 & .608 & 6.874 & .000 & .921 & 1.086 \\
\hline & SuasanaToko & .221 & .081 & .241 & 2.715 & .008 & .914 & 1.094 \\
\hline & Lokasi & .203 & .130 & .134 & 1.570 & .121 & .992 & 1.009 \\
\hline
\end{tabular}

Sumber: Output SPSS Ver.22, 2019

Diketahui bahwa nilai Tolerance dan VIF ketiga variabel pada penelitian ini nilai Tolerance $>$ dari 0,1 dan Nilai VIF $<$ dari 10, maka dapat disimpulkan bahwa tidak terjadi gejala Multikolinieritas antar variabel bebas.

\section{Uji Heteroskedastisitas}

Menurut (Duwi Priyatno, 2017:126), Heteroskedastisitas adalah varian residual yang tidak sama pada semua pengamatan didalam model regresi. Regresi yang baik seharusnya tidak terjadi heteroskedastisitas. 


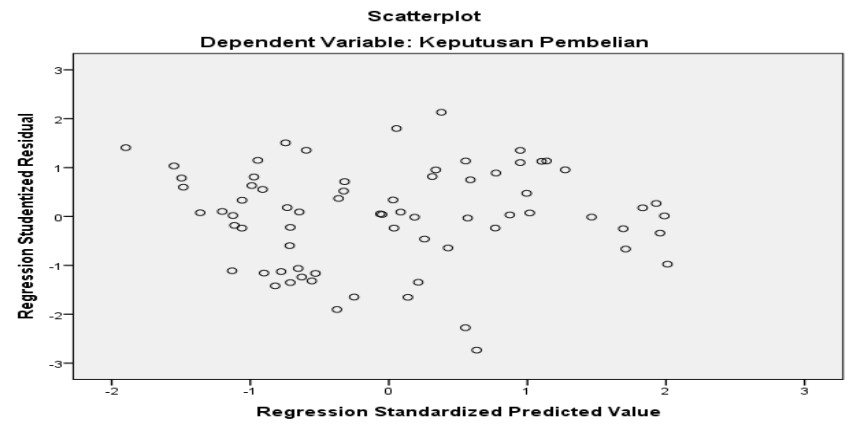

Gambar 1 Hasil Uji Heteroskedastisitas Sumber: Output SPSS Ver.22, 2019

Menggunakan grafik scaterplot menunjukkan bahwa titik membentuk pola tidak jelas, dan titik-titik menyebar diatas dan dibawah menyebar secara acak, dibawah serta diatas angka 0 pada sumbu Y, dan tidak mempunyai pola yang teratur. Hal ini dapat disimpulkan bahwa tidak terjadi heteroskedastisitas, sehingga model regresi layak dipakai untuk memprediksi dan peneliti dapat melanjutkan pengujian selanjutnya.

\section{Uji Autokorelasi}

Menurut (Duwi Priyatno, 2017:123), autokorelasi merupakan korelasi antara anggota observasi yang disusun menurut waktu atau tempat.Model regresi yang baik seharusnya tidak terjadi autokorelasi.Metode pengujian menggunakan uji Durbin Watson (DW test).

Tabel 5

Hasi Uji Autokorelasi Model Summary ${ }^{\mathrm{b}}$

\begin{tabular}{|l|l|l|l|l|l|}
\hline Model & $R$ & R Square & $\begin{array}{l}\text { Adjusted R } \\
\text { Square }\end{array}$ & $\begin{array}{l}\text { Std. Error of } \\
\text { the Estimate }\end{array}$ & $\begin{array}{l}\text { Durbin- } \\
\text { Watson }\end{array}$ \\
\hline 1 & $.719^{\mathrm{a}}$ & .518 & .496 & 5.401 & 2.104 \\
\hline
\end{tabular}

Sumber: Output SPSS Ver.22, 2019

Menunjukkan bahwa jumlah sampel $(\mathrm{n})=71$, dan jumlah variabel independen $(\mathrm{k})=$ 3, dengan level signifikansi 5\%. Nilai DL dan DU dapat diperoleh $\mathbf{D U}=\mathbf{1 . 7 0 4 1}$ dan $\mathbf{D L}=$ 1.5284, jadi nilai 4-DU $=\mathbf{2 . 2 9 5 9}$. Sehingga nilai $\mathrm{DU}<\mathrm{DW}<4$-DU $(1.7041<2.104<$ 2.2959) Ho diterima yang berarti tidak terjadi autokorelasi pada model regresi.

\section{Uji Korelasi dan Regresi Linier Berganda}

\section{Uji Korelasi}

Analisis korelasi adalah hubungan antara dua variabel. Dalam perhitungan korelasi, akan diperoleh koefisien korelasi yang menunjukan keeratan hubungan antar dua variabel tersebut. 
Tabel 6

Hasil Uji Korelasi

Correlations

\begin{tabular}{|ll|l|l|l|l|}
\hline & & $\begin{array}{l}\text { Keputusan } \\
\text { Pembelian }\end{array}$ & $\begin{array}{l}\text { Kualitas } \\
\text { Pelayanan }\end{array}$ & Suasana Toko & Lokasi \\
\hline $\begin{array}{ll}\text { Keputusan } \\
\text { Pembelian }\end{array}$ & Pearson Correlation & 1 & $.672^{* *}$ & $.399^{* *}$ & .096 \\
& Sig. (2-tailed) & & .000 & .001 & .425 \\
& $\mathrm{~N}$ & 71 & 71 & 71 & 71 \\
\hline Kualitas & Pearson Correlation & $.672^{* *}$ & 1 & $.281^{*}$ & -.025 \\
Pelayanan & Sig. (2-tailed) & .000 & & .018 & .835 \\
& N & 71 & 71 & 71 & 71 \\
\hline Suasana Toko & Pearson Correlation & $.399^{* *}$ & $.281^{*}$ & 1 & -.092 \\
& Sig. (2-tailed) & .001 & .018 & & .445 \\
& N & 71 & 71 & 71 & 71 \\
\hline Lokasi & Pearson Correlation & .096 & -.025 & -.092 & 1 \\
& Sig. (2-tailed) & .425 & .835 & .445 & \\
& N & 71 & 71 & 71 & 71 \\
\hline
\end{tabular}

Sumber: Output SPSS Ver.22, 2019

Berdasarkan tabel 6 angka koefisien korelasi positif, menunjukkan hubungan positif yang merupakan hasil uji korelasi, maka dapat di tarik kesimpulan yaitu:

a. Koefisien korelasi antara Kualitas Pelayanan (X1) dengan Keputusan Pembelian (Y) sebesar 0,672 mendekati 0 dengan sigifikansi $0,000<0,05$ menunjukkan Kualitas Pelayanan memiliki korelasi yang cukup kuat terhadap Keputusan Pembelian.

b. Koefisien korelasi antara Suasana Toko (X2) dengan Keputusan Pembelian (Y) sebesar 0,399 mendekati 0 dengan sigifikansi 0,001 $<0,05$ menunjukkan Suasana Toko memiliki korelasi yang cukup rendah terhadap Keputusan Pembelian.

c. Koefisien korelasi antara Lokasi (X3) dengan Keputusan Pembelian (Y) sebesar 0,096 mendekati 0 dengan sigifikansi 0,425 $>0,05$ menunjukkan Lokasi memiliki korelasi yang sangat rendah terhadap Keputusan Pembelian.

\section{Uji Regresi Linier Berganda}

Menurut (Duwi Priyanto, 2017:169), Regresi Linear Berganda digunakan untuk mengetahui seberapa besar pengaruh variabel independen terhadap variabel dependen.

\section{Tabel 7}

\section{Hasil Uji Regresi Linier Berganda}

\section{Coefficients ${ }^{\mathrm{a}}$}

\begin{tabular}{|c|c|c|c|c|c|c|c|c|}
\hline \multirow{2}{*}{\multicolumn{2}{|c|}{ Model }} & \multicolumn{2}{|c|}{$\begin{array}{l}\text { Unstandardized } \\
\text { Coefficients } \\
\end{array}$} & \multirow{2}{*}{$\begin{array}{l}\text { Standardized } \\
\text { Coefficients } \\
\text { Beta } \\
\end{array}$} & \multirow[b]{2}{*}{$\mathrm{t}$} & \multirow[b]{2}{*}{ Sig. } & \multicolumn{2}{|c|}{$\begin{array}{l}\text { Collinearity } \\
\text { Statistics }\end{array}$} \\
\hline & & B & Std. Error & & & & Tolerance & VIF \\
\hline & (Constant) & 5.148 & 6.256 & & .823 & .413 & & \\
\hline & Kualitas Pelayanan & .435 & .063 & .608 & 6.874 & .000 & .921 & 1.086 \\
\hline & Suasana Toko & .221 & .081 & .241 & 2.715 & .008 & .914 & 1.094 \\
\hline & Lokasi & .203 & .130 & .134 & 1.570 & .121 & .992 & 1.009 \\
\hline
\end{tabular}

Sumber: Output SPSS Ver.22, 2019

Tabel 7 menunjukkan hasil uji regresi linier berganda, dapat diperoleh persamaan regresi sebagai berikut:

$$
\mathrm{Y}=5,148+0,435 \mathrm{X}_{1}+0,221 \mathrm{X}_{2}+0,203 \mathrm{X}_{3}+\mathrm{e}
$$


Dari hasil analisis dan persamaan regresi linier berganda tersebut dapat diambil kesimpulan sebagai berikut:

a. Nilai Konstanta adalah 5,148 yang artinya jika Kualitas Pelayanan, Suasana Toko, dan Lokasi terhadap Keputusan Pembelian nilainya 0, maka Keputusan Pembelian akan bernilai sebesar 5,148.

b. Koefisien Regresi Kualitas Pelayanan (X1) bersifat positif sebesar 0,435 yang artinya jika variabel Kualitas Pelayanan meningkat 1 satuan, maka akan meningkatkan Keputusan Pembelian sebesar 0,435 dengan asumsi variabel lain tetap.

c. Koefisien Regresi Suasana Toko (X2) bersifat positif sebesar 0,221 yang arinya jika variabel Suasana Toko meningkat 1 satuan, maka akan meningkatkan Keputusan Pembelian sebesar 0,221 dengan asumsi variabel lain tetap.

d. Koefisien Regresi Lokasi (X3) bersifat positif sebesar 0,203 yang arinya jika variabel Lokasi meningkat 1 satuan, maka akan meningkatkan Keputusan Pembelian sebesar 0,203 dengan asumsi variabel lain tetap.

\section{Uji Hipotesis}

\section{Uji F}

Menurut Duwi Priyatno (2017:179) uji F (Annova)yaitu uji koefisien regresi secara bersama-sama untuk menguji signifikasi pengaruh beberapa variabel independen terhadap variabel dependen.

\section{Tabel 8}

Hasil Uji F

ANOVA ${ }^{\mathrm{a}}$

\begin{tabular}{|ll|l|l|l|l|l|}
\hline Model & & Sum of Squares & Df & Mean Square & F & Sig. \\
\hline 1 & Regression & 2097.257 & 3 & 699.086 & 23.964 & $.000^{\mathrm{b}}$ \\
& Residual & 1954.518 & 67 & 29.172 & & \\
& Total & 4051.775 & 70 & & & \\
\hline
\end{tabular}

Sumber: Output SPSS Ver.22, 2019

Pada tabel 4.15 menunjukkan hasil uji $\mathrm{F}$ dengan nilai sebesar 23,964 $>2.742$ dan nilai signifikansi sebesar $0,000<005$ maka Ho ditolak. Yang artinya variabel independen (Kualiatas Pelayanan, Suasana Toko, dan Lokasi) secara simultan berpengaruh positif dan signifikan terhadap variabel dependen (Keputusan Pembelian).

\section{Uji t}

Menurut (Duwi Priyatno, 2017: 161), uji t hitung adalah pengujian signifikan untuk mengetahui pengaruh variabel $\mathrm{x}$ terhadap $\mathrm{y}$, apakah berpengaruh signifikan atau tidak.

\section{Tabel 9 \\ Hasil Uji t}

Coefficients $^{\mathrm{a}}$

\begin{tabular}{|c|c|c|c|c|c|c|c|c|}
\hline \multirow[b]{2}{*}{ Model } & & \multicolumn{2}{|c|}{$\begin{array}{l}\text { Unstandardized } \\
\text { Coefficients }\end{array}$} & \multirow{2}{*}{$\begin{array}{l}\text { Standardized } \\
\text { Coefficients } \\
\text { Beta } \\
\end{array}$} & \multirow[b]{2}{*}{$\mathrm{T}$} & \multirow[b]{2}{*}{ Sig. } & \multicolumn{2}{|c|}{$\begin{array}{l}\text { Collinearity } \\
\text { Statistics }\end{array}$} \\
\hline & & $\mathrm{B}$ & Std. Error & & & & Tolerance & VIF \\
\hline \multirow[t]{4}{*}{1} & (Constant) & 5.148 & 6.256 & & .823 & .413 & & \\
\hline & Kualitas Pelayanan & .435 & .063 & .608 & 6.874 & .000 & 921 & 1.086 \\
\hline & Suasana Toko & .221 & .081 & .241 & 2.715 & .008 & .914 & 1.094 \\
\hline & Lokasi & .203 & .130 & .134 & 1.570 & .121 & .992 & 1.009 \\
\hline
\end{tabular}

Sumber: Output SPSS Ver.22, 2019

Hasil uji t dari 4.14 dijelaskan sebagai berikut: 
a. Variabel Kualitas Pelayanan $(X 1)$ nilai $t$ hitung $>\mathrm{t}$ tabel $(6,874>1,996)$ dan nilai signifikansi $(0,000<0,05)$ maka Ho ditolak, yang artinya Kualitas Pelayanan berpengaruh signifikan terhadap Keputusan Pembelian.

b. Variabel Suasana Toko $(\mathrm{X} 2)$ nilai t hitung $>\mathrm{t}$ tabel $(2,715>1,996)$ dan nilai signifikansi $(0,008<0,05)$ maka Ho ditolak, yang artinya Suasana Toko berpengaruh signifikan terhadap Keputusan Pembelian.

c. Variabel Lokasi $(\mathrm{X} 3)$ nilai $t$ hitung $<\mathrm{t}$ tabel $(1,570<1,996)$ dan nilai signifikansi $(0,121$ $<0,05)$ maka Ho diterima, yang artinya Lokasi tidak berpengaruh signifikan terhadap Keputusan Pembelian.

\section{Uji Koefisien Determinasi}

Koefisien Determinasi digunakan untuk menjelaskan proporsi variabel terikat (dependen) yang mampu dijelaskan oleh variasi variabel bebasnya (independen).

\section{Tabel 10}

Hasil Uji Koefisien Determinasi Model Summary ${ }^{b}$

\begin{tabular}{|l|l|l|l|l|l|}
\hline Model & R & R Square & $\begin{array}{l}\text { Adjusted } \\
\text { Square }\end{array}$ & $\begin{array}{l}\text { Std. Error of the } \\
\text { Estimate }\end{array}$ & Durbin-Watson \\
\hline 1 & $.719^{\mathrm{a}}$ & .518 & .496 & 5.401 & 2.104 \\
\hline
\end{tabular}

Sumber: Output SPSS Ver.22, 2019

Dari tabel 10 dapat dilihat bahwa nilai Adjusted R Square sebesar 0,496 (49\%) artinya menunjukkan bahwa presentase sumbangan pengaruh variabel independen terhadap variabel adalah sebesar $49,6 \%$ sedangkan sisanya sebesar $50,4 \%$ dipengaruhi oleh variabel lain (keberagaman produk, promosi, citra merek, dan lain-lain) yang tidak termasuk dalam dalam penelitian ini.

\section{KESIMPULAN}

Berdasarkan hasil penelitian ini bertujuan untuk menguji pengaruh dari variabel Kualitas Pelayanan, Suasana Toko, dan Lokasi terhadap Keputusan Pembelian. Kesimpulan dari penelitian ini adalah:

1. Kualitas Pelayanan (X1), Suasana Toko (X2), dan Lokasi (X3) pada Indomaret Jalan Sultan Iskandar Muda Kebayoran Lama berpengaruh signifikan terhadap Keputusan Pembelian. Pengaruhnya sebesar $49 \%$ sedangkan sisanya 51\% dipengaruhi variabel lain (Kualitas Produk, Promosi, Citra Merek, dan lain-lain) yang tidak termasuk dalam dalam penelitian ini.

2. Kualitas Pelayanan (X1) pada Indomaret Jalan Sultan Iskandar Muda Kebayoran Lama berpengaruh signifikan terhadap Keputusan Pembelian.

3. Suasana Toko (X2) pada Indomaret Jalan Sultan Iskandar Muda Kebayoran Lama berpengaruh signifikan terhadap Keputusan Pembelian.

4. Lokasi (X3) pada Indomaret Jalan Sultan Iskandar Muda Kebayoran Lama tidak berpengaruh dan tidak signifikan terhadap Keputusan Pembelian.

\section{SARAN}

Adapun saran-saran yang dapat diberikan sebagai berikut:

1. Indomaret Jalan Sultan Iskandar Muda Kebayoran Lama harus dapat mempertahankan dan menjaga kualitas pelayanan yang dimiliki, agar dapat menjaga konsistensi kesetiaan yang ditunjukkan oleh konsumen. Hal ini diharapkan mampu meningkatkan keputusan pembelian di Indomaret Jalan Sultan Iskandar Muda Kebayoran Lama. 
2. Indomaret Jalan Sultan Iskandar Muda Kebayoran Lama lebih mempertahankan dan meningkatkan lagi kenyamanan untuk memanjakan dan membuat nyaman konsumen saat berbelanja, dengan cara penawaran yang menarik, pengaturan cahaya, warna, backsound musik, kebersihan yang harus tetap dijaga, sirkulasi udara serta aroma yang diharapkan mampu menciptakan perasaan saat berbelanja. Hal tersebut perlu dilakukan karena bertujuan untuk mempertahankan dan menarik minat konsumen baru agar Indomaret Jalan Sultan Iskandar Muda Kebayoran Lama dapat terus berkembang dan mampu bersaing dengan para kompetitor lainnya yang sudah bernama besar.

3. Lokasi yang tidak berpengaruh dengan Keputusan Pembelian, berdasarkan hasil responden pada dimensi visibilitas pada indikator "Tersedia ruang parkir yang aman dan nyaman" memiliki nilai terendah 3,56, karena hal tersebut sebaiknya Indomaret Jalan Sultan Iskandar Muda Kebayoran Lama perlu memperhatikan ruang parkir yang luas, aman dan nyaman dengan cara perluasan area parkir, peningkatan keamanan pada tempat parkir konsumen, serperti tersedianya kamera pemantau (CCTV) di area tempat parkir, dan terutama dalam hal kondisi jalanan di area tempat parkir perlu diperbaiki agar memudahkan konsumen yang membawa kendaraan pribadi khususnya mobil dan motor. Hal-hal tersebut sangat berpengaruh terhadap Keputusan Pembelian konsumen Indomaret Jalan Sultan Iskandar Muda Kebayoran Lama.

\section{DAFTAR PUSTAKA}

\section{Sumber Buku}

Christina Widya, Utami. 2012. Manajemen Ritel, Edisi 2. Jakarta : Salemba Empat. Hurriyati, Ratih. 2015. Bauran Pemasaran dan Loyalitas Konsumen.Bandung: Alfabetha

Kotler, Philip dan Armstrong, Gary. 2012. Principles of Marketing. 15th edition.New Jersey: Prentice Hall.

Priyatno, Duwi. 2017. SPSS 22 Panduan Praktis Olah Data Menggunakan SPSS. Andi.Yogyakarta.

Sugiyono. 2016. Metode Penelitian Kuantitatif, Kualitatif dan R\&D. Bandung: PT Alfabet.

Tjiptono, Fandy dan Gregorius Chandra. 2016. Service, Quality \& Satisfaction.Yogyakarta: Andi.

\section{Jurnal}

Affandi, Mohammad Yusuf. 2017. Pengaruh Kualitas Pelayanan, Atmosfer Toko, Dan Harga terhadap Keputusan Pembelian Di Ria Mart. Simki-Economic Vol. 01 No. 0.1

Polla, Febriano Clinton., Lisbeth Mananeke \& Rita N Taroreh. 2018. Pengaruh Harga, Promosi, Lokasi, dan Kualitas Pelayanan terhadap Keputusan Pembelian pada PT. Indomaret Manado Unit Jalan Sea. Vol.6 No.4, Hal. 3068 - 3077.

Rinna, Rahmawati., Musriha., Indah Noviandari. 2017. Pengaruh Suasana Toko (Store Atmosphere), Kualitas Pelayanan dan Merek Pribadi (Private Label) terhadap Keputusan Pembelian pada Toko Kue Liarah Surabaya Periode 2013-2015. Vol 3 Issue.

\section{Website}

Www.indomaret.co.id 